\title{
Dispositivos móveis e modelagem no ensino de Embriologia
}

\author{
Tatiana Montanari \\ Professora associada do Departamento de Ciências Morfológicas, ICBS, UFRGS, \\ t.montanari@bol.com.br
}

\begin{abstract}
Resumo: O ambiente virtual auladeembrio (http://www.ufrgs.br/auladeembrio) tem sido utilizado na disciplina de Embriologia do curso de Ciências Biológicas, como apoio didático-pedagógico nas aulas presenciais e no estudo extraclasse. A navegação foi construída com o programa Adobe Dreamweaver. O conteúdo é apresentado em telas do PowerPoint, ilustrado com fotografias macroscópicas ou obtidas em microscópio estereoscópico, de luz ou eletrônico, desenhos realizados com o Adobe Illustrator e mapas conceituais criados com o CmapTools. Exercícios elaborados com o programa Hot Potatoes foram incluídos para aumentar a interatividade e motivar a aprendizagem. Nas aulas práticas, suas imagens são consultadas pelos alunos em dispositivos móveis para apoiar a representação gráfica e em modelagem do desenvolvimento embrionário. Submetido à avaliação discente, verificou-se adesão ao ambiente virtual para o estudo da disciplina e sua contribuição para a aprendizagem. Pela oferta de informação atualizada, apresentada prioritariamente em linguagem visual e com recursos de interatividade, publicada livremente na rede, espera-se ter contribuído para qualificar o ensino dessa disciplina e, por conseguinte, das Ciências Morfológicas.
\end{abstract}

Palavras-chave: Embriologia, Morfologia, ambiente virtual de aprendizagem, tecnologia educacional, educação à distância.

\section{Mobile devices and modeling in the embryology classroom teaching}

\begin{abstract}
The auladeembrio virtual environment (http://www.ufrgs.br/auladeembrio) has been used in the Embryology course from the undergraduate Biological Sciences, as didactic and pedagogical support in the classroom and e-learning. Web browsing was made with Adobe Dreamweaver software. The subject is presented in PowerPoint screens, illustrated with macroscopic images, photographs obtained by stereo, light and electron microscopy, drawings made by Adobe Illustrator and concept maps created by CmapTools. Exercises elaborated by Hot Potatoes program were included to increase interactivity and motivate learning. At the practical classes, its images are researched by students at mobile devices for supporting the graphic representation or the modeling on the embryonic development. The evaluation by students demonstrated its use for studying the subject and its contribution for the process of learning. Because this virtual environment exhibits updated information, visual language and interactivity, and it is published freely in web, I hope contributing to improve the teaching of Embryology and consequently of the Morphological Sciences.
\end{abstract}

Keywords: Embryology, Morphology, learning virtual environment, educational technology, e-learning. 


\section{INTRODUÇÃO}

Embriologia é o estudo descritivo ou experimental do desenvolvimento embrionário. Não se restringe ao ser humano (Embriologia humana); quando aborda os diferentes grupos animais, é denominada Embriologia comparada. Atualmente ela é também chamada Biologia do desenvolvimento, devido ao grande avanço em Biologia molecular e celular para explicar os mecanismos responsáveis pelo desenvolvimento normal e anormal (Balinsky, 1981, p.3-16; Browder et al., 1991; Carlson, 2002; Gilbert, 2013; Montanari, 2013; Carlson, 2014).

A Embriologia comparada não é tão contemplada nos livros-texto de graduação como a Embriologia humana, porque o seu ensino é limitado ao curso de Ciências Biológicas, e o mercado editorial é menos atrativo que àquele da área médica. Livros clássicos, como Embriologia de Houillon (1972) e An introduction to Embryology de Balinsky (1981), não foram mais editados, e os últimos exemplares são negligenciados pelas novas gerações de universitários nas bibliotecas institucionais. Embryology: constructing the organism de Gilbert \& Raunio (1997), possivelmente o livro mais completo sobre o desenvolvimento dos diferentes grupos animais, não tem tradução em português. Destaca-se, entre os poucos títulos nacionais, o livro Embriologia de Garcia \& Garcia (2012), redigido durante a docência na Universidade Federal do Rio Grande do Sul (UFRGS) e adotado por várias instituições de ensino superior. O Departamento de Ciências Morfológicas da UFRGS mantém a tradição na produção na área com o livro digital Embriologia: texto, atlas e roteiro de aulas práticas (Montanari, 2013), que apresenta um texto conciso, ricamente ilustrado, direcionado para a graduação. Os livros de Biologia do desenvolvimento também são uma fonte importante sobre $o$ desenvolvimento animal, mas o texto enfatizando os aspectos moleculares faz com que eles pertençam mais ao escopo da Genética do que da Morfologia (Browder, 1991; Wolpert et al., 2008; Gilbert, 2013). Na rede, a situação não é muita diferente daquela encontrada na plataforma física. Ferreira \& Kempinas (2010), ao analisarem o conteúdo sobre "Embriologia comparada" no banco de dados Google, notaram uma abordagem superficial e sem preocupação didático-pedagógica.

A Embriologia faz parte das Ciências Morfológicas, que abrange ainda Biologia celular, Histologia e Anatomia. Essas disciplinas têm sofrido sistemática redução da carga horária nas reformas curriculares, e os recursos virtuais complementam a educação presencial e otimizam o tempo do professor e do aluno no processo de ensinoaprendizagem (Carlson, 2002; Samar \& Avila, 2007; Ferreira \& Kempinas, 2010; Ferreira, 2011; Santa-Rosa \& Struchiner, 2011).

O ambiente virtual auladeembrio (http://www.ufrgs.br/auladeembrio) foi desenvolvido para apoiar o processo didático-pedagógico nas aulas presenciais e no estudo extraclasse de Embriologia e pode ser usado pelo professor (professor - aluno) ou pelo aluno (tutor-aluno, aluno-aluno, aluno) do ensino médio ou superior. A Embriologia humana e comparada é abordada nas aulas práticas com a representação de preparados permanentes e atividades de modelagem, e o auladeembrio, acessado por dispositivos móveis, como tablet e smartphone, é a principal referência de apoio. A contribuição do ambiente virtual para a aprendizagem desse conteúdo foi avaliada pelos alunos da disciplina. 


\section{METODOLOGIA}

A disciplina Embriologia consiste em quatro créditos (duas horas-aula teóricas e duas horas-aula práticas) e é ofertada semestralmente para 50 alunos do curso de Ciências Biológicas. Contemplada pelo programa de Monitoria acadêmica a distância para disciplina presencial, a plataforma de aprendizagem Moodle foi implementada na disciplina, nos anos de 2009 a 2010. Nesse período, foi digitalizado o material utilizado nas aulas teóricas e práticas, como diapositivos, lâminas para retroprojeção, imagens de livros da área, fotografias de lâminas histológicas e de peças macroscópicas e ainda fotomicrografias e eletromicrografias obtidas em projetos de pesquisa. Usando o programa Adobe Illustrator e como modelo os originais escaneados dos livros-texto, ilustrações foram produzidas. Com essas imagens, foram feitas as primeiras versões das apresentações em PowerPoint. Tabelas, esquemas e mapas conceituais elaborados com o programa CmapTools foram incluídos para facilitar a compreensão. Questões de estudos dirigidos e de avaliações foram transformadas em exercícios com o software Hot Potatoes para a aplicação dos conceitos e aumentar a interatividade.

A partir das apresentações elaboradas para o Moodle, foi desenvolvido um ambiente virtual em HTML, com o programa Adobe Dreamweaver. Como atividade de extensão (produção e publicação), deu-se prosseguimento ao registro fotográfico do acervo e à elaboração dos desenhos com o Adobe Illustrator, a fim de substituir as imagens de livros, e à revisão e atualização do texto, com inserção de referências. $\mathrm{O}$ auladeembrio foi publicado na página da instituição: http://www.ufrgs.br/auladeembrio, com acesso livre. O contador ClustrMaps permite acompanhar a quantidade de acessos e a sua distribuição geográfica.

Os alunos da disciplina Embriologia do curso de Ciências Biológicas avaliaram o recurso virtual ao final do primeiro semestre letivo de 2016 e de 2017. Nesta última avaliação, itens a respeito do conteúdo de Embriologia comparada foram incluídos para compreender a sua contribuição para a aprendizagem.

\section{RESULTADOS E DISCUSSÃO}

O ambiente virtual auladeembrio foi produzido para apoiar o processo de ensinoaprendizagem de Embriologia nos cursos de graduação nas áreas Biológicas e da Saúde. Foi construído utilizando o programa Adobe Dreamweaver, visando oferecer navegação hipertextual amigável e interativa. Na tela inicial, o conteúdo de Embriologia pode ser acessado pelos seguintes tópicos no тепи: Histórico, Gametogênese, Transporte dos gametas e Fertilização, Desenvolvimento comparado e Desenvolvimento humano (Figura 1). O conteúdo é exibido em telas do PowerPoint, em formato PDF, organizado como apresentado em sala de aula e ricamente ilustrado com fotografias macroscópicas ou obtidas em microscópio estereoscópico, de luz ou eletrônico e desenhos realizados com o Adobe Illustrator (Figuras 2 a 4). Além do texto narrativo e das legendas, foram incluídos tabelas e mapas conceituais elaborados com o software CmapTools para facilitar a compreensão do assunto abordado. Para aumentar a interatividade e motivar a aprendizagem, foram agregados exercícios desenvolvidos com o Hot Potatoes (Figura 5). O recurso virtual tem sido utilizado na disciplina de Embriologia do curso de Ciências Biológicas desde 2010, sendo periodicamente revisado e atualizado, com acréscimo significativo de texto e imagens. No final do primeiro semestre letivo de 2016 e de 2017, foi submetido à avaliação discente. Em 2016, de 43 alunos matriculados, 37 alunos responderam o questionário, e, em 2017, de 41 alunos matriculados, 35 alunos responderam-no (Tabela 1). 

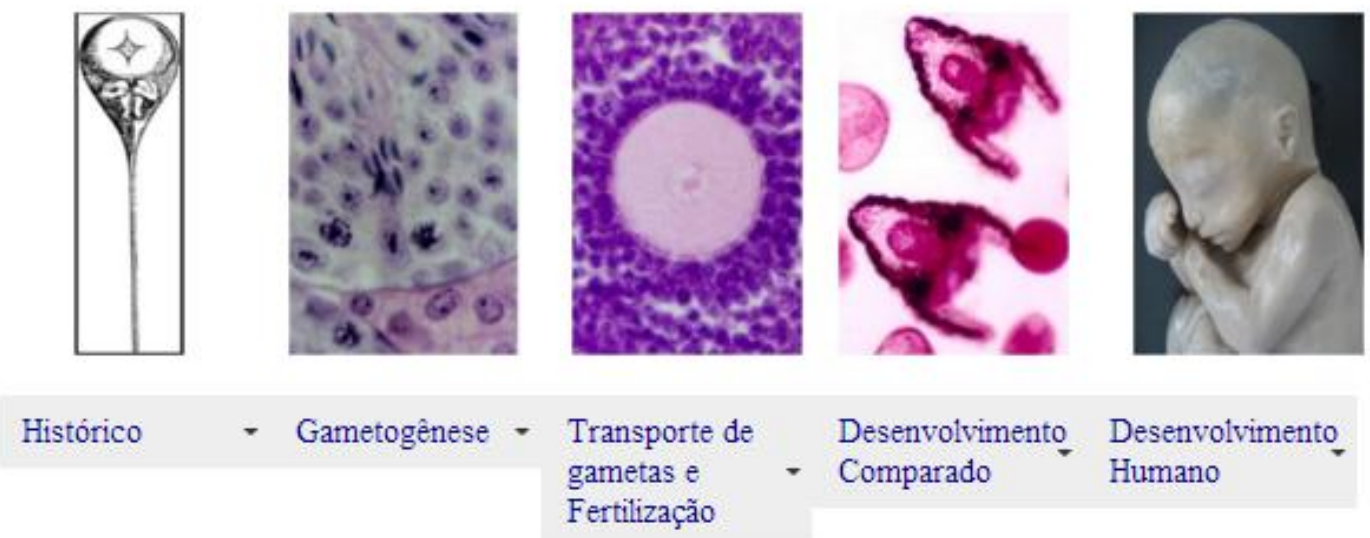

Desenvolvimento

- Comparado

Desenvolvimento, Humano

Figura 1 - Tela inicial com o menu e os créditos do ambiente virtual de aprendizagem.

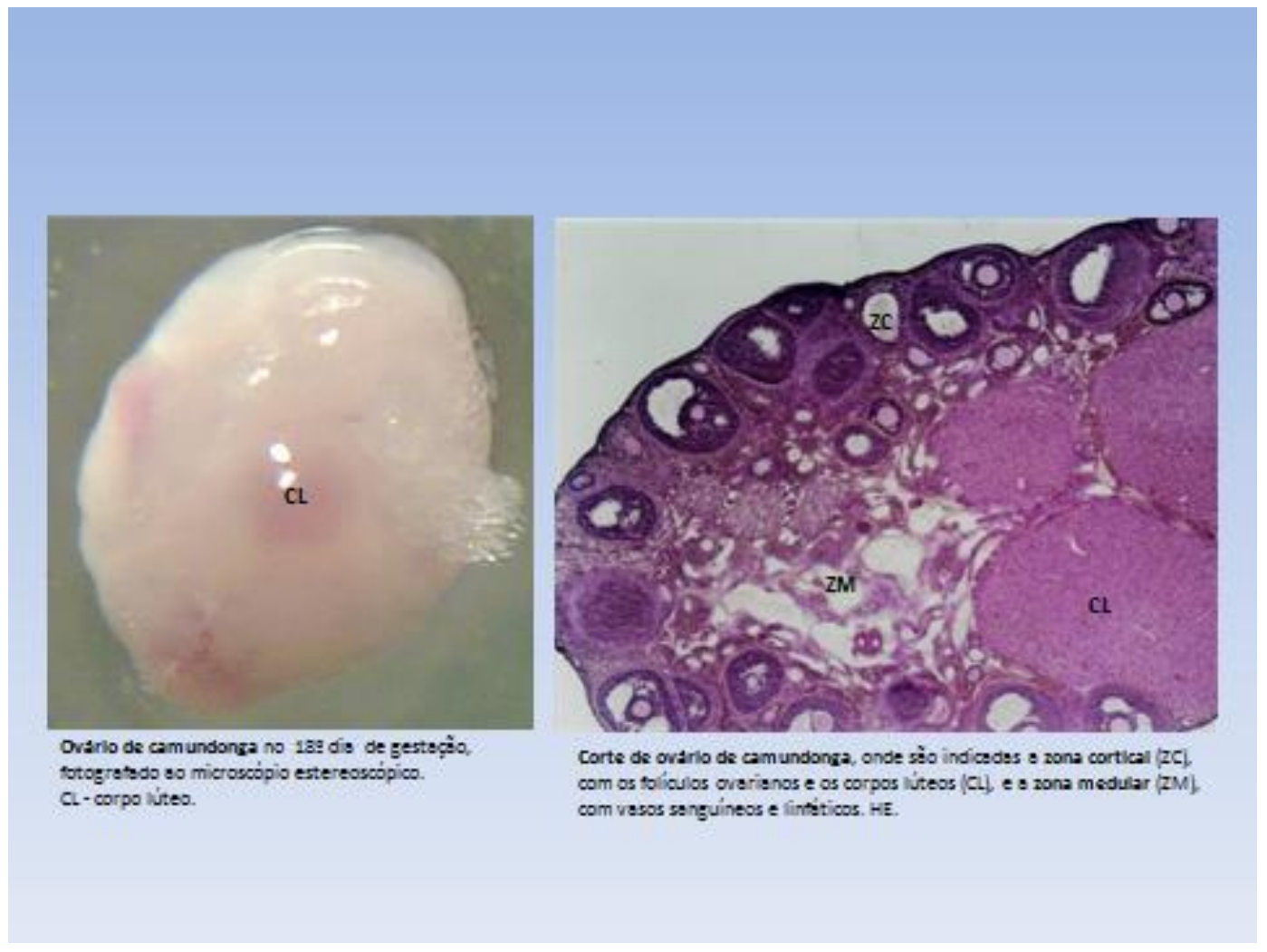

Figura 2 - Tela do tópico Gametogênese, exemplificando a forma de apresentação: fotografias obtidas ao microscópio estereoscópico e de luz e legenda explicativa. 


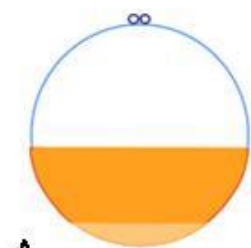

A

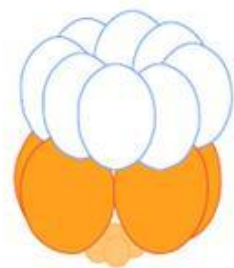

E

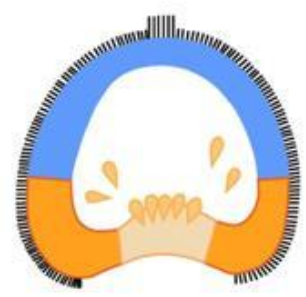

I

T. G. Laureirg , E. Leite e T. Mantanari
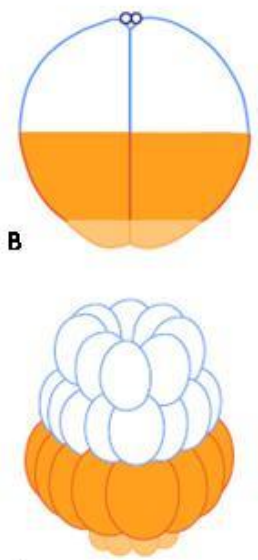

$\mathbf{F}$

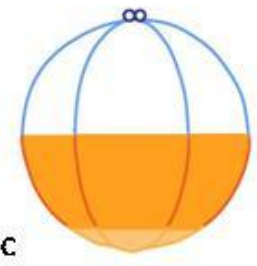

D

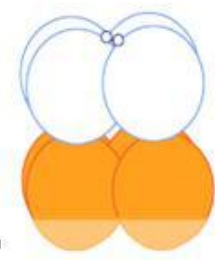

G

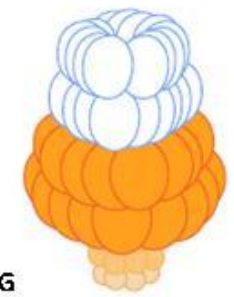

H

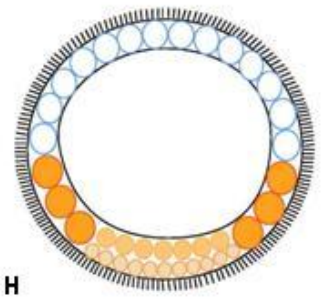

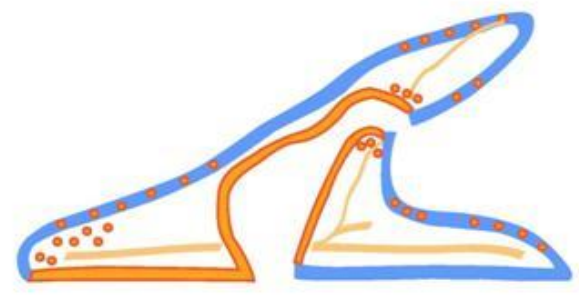

K

Baseada em Hauillan, 1972. p. 13.

Figura 3 - Da seção Desenvolvimento comparado, desenhos realizados com o Adobe Illustrator sobre o desenvolvimento de equinodermos (ouriço-do-mar).

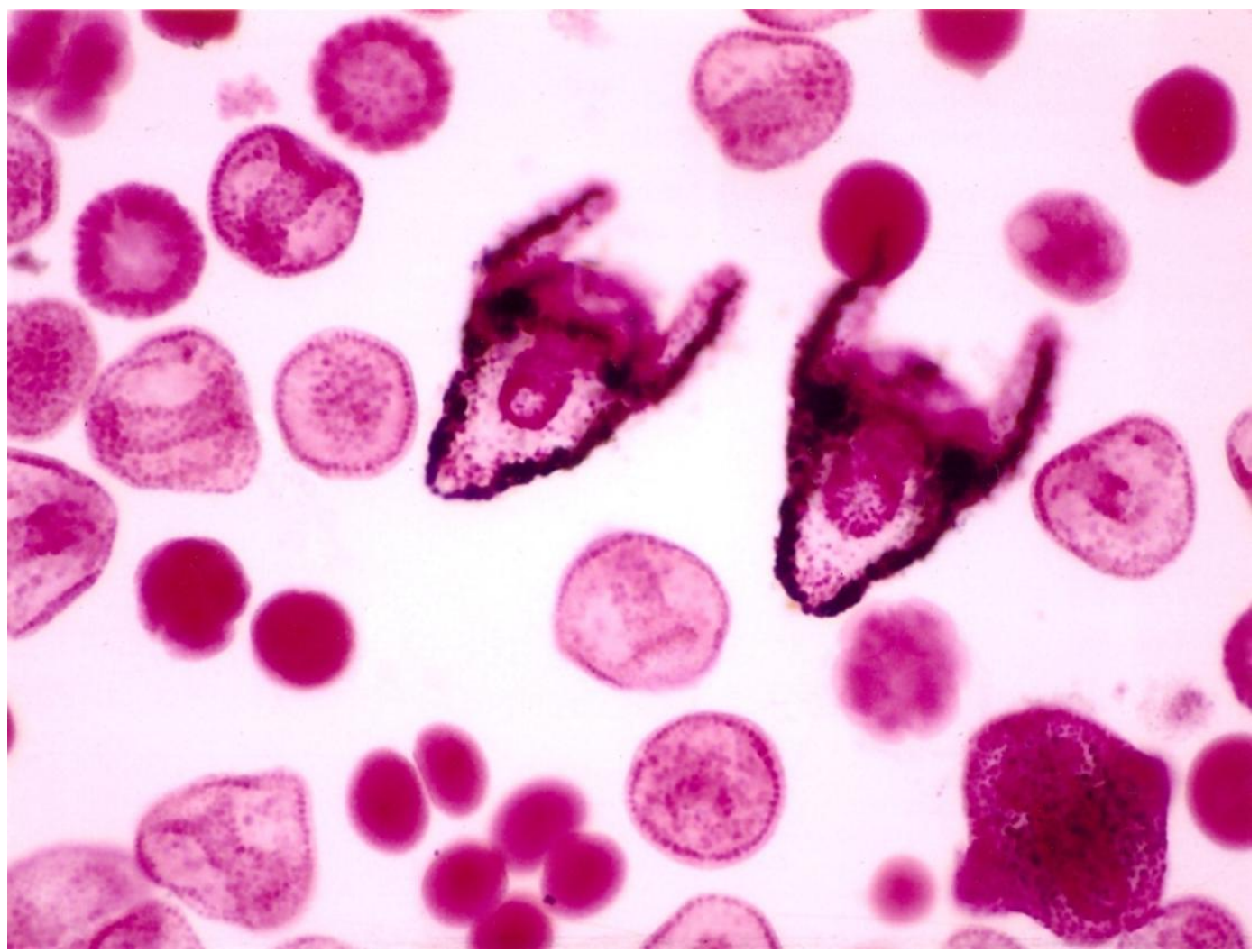

Figura 4 - Fotomicrografia mostrando várias etapas do desenvolvimento de ouriço-domar: ovo, embriões de duas e quatro células, mórula, blástula, gástrula e larva plúteo. 


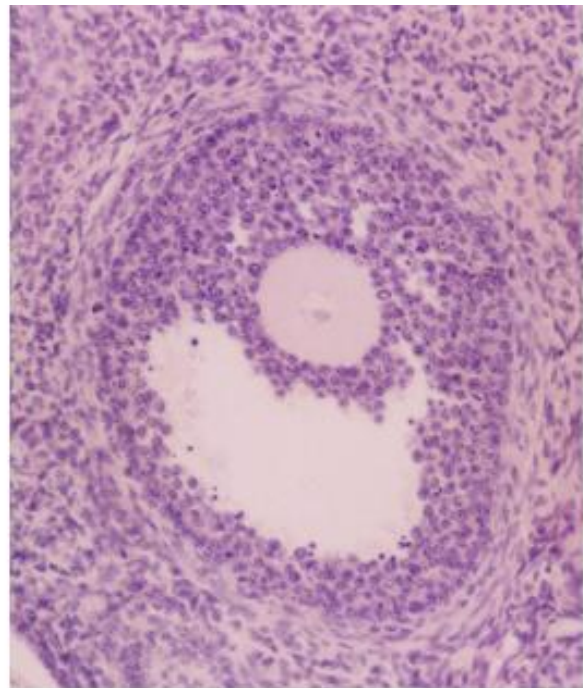

folículo em crescimento antra

???

folículo em crescimento unilaminar

folículo em crescimento multilaminar

folículo maduro

folículo em crescimento antral

folículo primordial

folículo atrésico

Figura 5 - Exercício de associação, com diagnóstico de imagem, sobre o conteúdo de Gametogênese.

Tabela 1 - Resultados da avaliação discente do ambiente virtual auladeembrio.*

\begin{tabular}{|c|c|c|c|c|}
\hline Critério avaliado & Sim & Parcialmente & Não & $\begin{array}{l}\text { Não } \\
\text { responderam }\end{array}$ \\
\hline $\begin{array}{l}\text { Utilizou livro-texto de Histologia para estudar para a } \\
\text { disciplina? }\end{array}$ & $50 \%$ & ------ & $50 \%$ & \\
\hline $\begin{array}{l}\text { Utilizou livro-texto de Embriologia para estudar } \\
\text { para a disciplina? }\end{array}$ & $94 \%$ & ------ & $6 \%$ & \\
\hline $\begin{array}{l}\text { Utilizou o auladeembrio para estudar para a } \\
\text { disciplina? }\end{array}$ & $72 \%$ & $28 \%$ & & \\
\hline $\begin{array}{l}\text { O auladeembrio contribuiu para a aprendizagem do } \\
\text { conteúdo? }\end{array}$ & $89 \%$ & $11 \%$ & & \\
\hline O auladeembrio motivou o estudo do conteúdo? & $46 \%$ & $36 \%$ & $10 \%$ & $8 \%$ \\
\hline Os arquivos em pdf foram baixados com rapidez? & $86 \%$ & $10 \%$ & & $4 \%$ \\
\hline $\begin{array}{l}\text { As suas fotografias contribuíram para a } \\
\text { compreensão do conteúdo? }\end{array}$ & $76 \%$ & $21 \%$ & $1 \%$ & $2 \%$ \\
\hline $\begin{array}{l}\text { As suas ilustrações contribuíram para a compreensão } \\
\text { do conteúdo? }\end{array}$ & $72 \%$ & $24 \%$ & $3 \%$ & $1 \%$ \\
\hline As imagens apresentaram boa qualidade de nitidez? & $86 \%$ & $11 \%$ & $1 \%$ & $2 \%$ \\
\hline $\begin{array}{l}\text { Havia setas e outras indicações suficientes para a } \\
\text { compreensão das imagens? }\end{array}$ & $51 \%$ & $43 \%$ & $6 \%$ & \\
\hline As legendas eram compreensíveis? & $79 \%$ & $20 \%$ & $1 \%$ & \\
\hline O texto explicativo era compreensível? & $68 \%$ & $31 \%$ & $1 \%$ & \\
\hline O tamanho da letra era adequado? & $86 \%$ & $7 \%$ & $7 \%$ & \\
\hline Realizou os exercícios? & $31 \%$ & $39 \%$ & $29 \%$ & $1 \%$ \\
\hline $\begin{array}{l}\text { Os exercícios contribuíram para a compreensão do } \\
\text { conteúdo? }\end{array}$ & $33 \%$ & $35 \%$ & $6 \%$ & $26 \%$ \\
\hline
\end{tabular}


Aplicou o conteúdo do auladeembrio em outras disciplinas ou atividades da vida acadêmica?

Acredita que aplicará o conteúdo do auladeembrio na vida pessoal ou profissional?

* Disciplina Embriologia (Ciências Biológicas), 72 alunos.

Houve uma grande adesão ao recurso virtual para o estudo da disciplina e, de forma gratificante, concordância praticamente unânime sobre sua contribuição para a aprendizagem. A linguagem visual (fotografias e ilustrações) favoreceu a compreensão do conteúdo e foi considerada pelos alunos com excelente qualidade de nitidez e relativamente bem sinalizada. Foi sugerida a inclusão de animações, imagens em 3D e ilustrações interativas. A maioria dos alunos considerou o texto explicativo e as legendas compreensíveis, expostos com fonte de tamanho adequado, mas houve quem considerasse o texto em demasia e sugerisse a apresentação em tópicos, com letra maior (assim, era na primeira versão). De forma surpreendente, o recurso de interatividade do ambiente virtual, que consistia nos exercícios, não foi utilizado em totalidade pelos alunos, prejudicando a avaliação da sua contribuição para a compreensão do conteúdo. Em contrapartida, houve sugestões solicitando mais exercícios e maior interatividade. Com o apoio do programa de Monitoria acadêmica a distância para disciplina presencial - SEAD/PROGRAD, exercícios estão sendo elaborados e serão agregados ao ambiente virtual.

A preocupação com a oferta de imagens, tanto no que se refere à quantidade como à qualidade, visava facilitar a compreensão do conteúdo; meta alcançada segundo a avaliação discente. A Embriologia é bastante complexa, rica em detalhes e com nomenclatura própria e, assim como as demais disciplinas das Ciências Morfológicas, foi construída basicamente pelos resultados de experimentos envolvendo a observação em microscopia, seja ao microscópio estereoscópico (lupa), de luz (antigamente denominado microscópio óptico) ou eletrônico. O aluno deve conhecer (compreender e interpretar) tanto os registros fotográficos desses trabalhos como as ilustrações exibidas nos livros-texto da área. Por isso, a informação visual teve prioridade no planejamento do objeto. Além disso, vários estudos mostram a importância dessa linguagem na aprendizagem (Mayer \& Gallini, 1990; Heyden, 2004; Stith, 2004; McClean et al., 2005).

Em 2017, além da avaliação desses critérios, o tópico Embriologia comparada foi analisado para verificar a contribuição das ilustrações para a compreensão do conteúdo e para a realização da atividade prática. O desenvolvimento embrionário dos equinodermos, dos protocordados e dos anfíbios é representado em modelagem, sendo executadas as seguintes etapas: o ovo, a clivagem, a gastrulação e a larva. São utilizadas quatro cores de massa de modelar para representar o ovo, e essas cores são mantidas nas etapas subsequentes para acompanhar o destino das células-filhas do ovo em folhetos embrionários e, posteriormente, em tecidos e órgãos. As ilustrações do auladeembrio são usadas como referência pelos alunos para a realização da atividade. Elas são consultadas através de dispositivos móveis, como tablet ou smartphone. Ainda verificou-se, na enquete, a possibilidade da aplicação das ilustrações e da atividade de modelagem no ensino médio para abordar esse conteúdo (Tabela 2). 
Tabela 2 - Resultados da avaliação discente do ambiente virtual auladeembrio sobre o conteúdo de Embriologia comparada.*

\begin{tabular}{|l|c|c|c|c|}
\hline Critério avaliado & Sim & Parcialmente & Não & $\begin{array}{c}\text { Não } \\
\text { responderam }\end{array}$ \\
\hline $\begin{array}{l}\text { As ilustrações contribuíram para a compreensão do } \\
\text { conteúdo? }\end{array}$ & $63 \%$ & $28 \%$ & $3 \%$ & $6 \%$ \\
\hline $\begin{array}{l}\text { As cores foram coerentes ao longo do } \\
\text { desenvolvimento de cada animal? }\end{array}$ & $88 \%$ & $3 \%$ & $3 \%$ & $6 \%$ \\
\hline $\begin{array}{l}\text { Os desenhos facilitaram a representação em massa } \\
\text { de modelar? }\end{array}$ & $74 \%$ & $20 \%$ & $3 \%$ & $3 \%$ \\
\hline $\begin{array}{l}\text { Essas ilustrações poderiam ser usadas no ensino } \\
\text { médio? }\end{array}$ & $51 \%$ & $31 \%$ & $14 \%$ & $4 \%$ \\
\hline $\begin{array}{l}\text { A atividade de modelagem poderia ser usada no } \\
\text { ensino médio para abordar esse conteúdo? }\end{array}$ & $83 \%$ & $9 \%$ & $6 \%$ & $2 \%$ \\
\hline $\begin{array}{l}\text { Você gostou de realizar as aulas práticas de } \\
\text { modelagem sobre o desenvolvimento animal? }\end{array}$ & $63 \%$ & $31 \%$ & $3 \%$ & $3 \%$ \\
\hline * Disciplina Embriologia (Ciências Biológicas), 35 alunos. & & & \\
\hline
\end{tabular}

$\mathrm{Na}$ avaliação discente, verificou-se que o ambiente virtual, através das suas ilustrações, foi importante no processo de aprendizagem do conteúdo de Embriologia comparada e que a representação em modelagem do desenvolvimento animal pode ser replicada como atividade prática no ensino médio.

O estudo da Embriologia é especialmente importante para os profissionais da Saúde, que, além do desenvolvimento normal, devem saber o aspecto clínico das anormalidades. Temas como fertilização assistida, clonagem, células-tronco embrionárias são pautados com frequência na mídia, pressionando-os ainda mais a buscar conhecimento sobre o assunto para atender a demanda do público-leigo (Carlson, 2002). As pesquisas em células-tronco e clonagem também fizeram ressurgir o interesse de biólogos, biomédicos e veterinários por essa disciplina. Atualmente o reconhecimento da correlação entre o vírus Zika e o aumento na incidência de microcefalia expõe mais uma vez o seu lado trágico, evidenciado com a descoberta de defeitos congênitos causados pelo vírus da rubéola em 1941 e pela talidomida nos anos de 1960 (Gregg, 1941; McBride, 1961; Lenz, 1962; Pfeiffer \& Kosenow, 1962; Garcia \& García-Fernández, 2003, p. 280; Carlson, 2014, p. 136, 138; Brito, 2015).

Como campo de pesquisa, devido aos grandes avanços em Biologia molecular e celular a partir dos anos de 1990, ela está em um período de mudanças sem precedentes em sua base de conhecimento (Carlson, 2002). Diferentes recursos de microscopia, técnicas de imunocitoquímica, cultura de células, análises bioquímicas e manipulações genéticas estão permitindo explicar os mecanismos responsáveis pelo desenvolvimento normal e anormal. A partir desses resultados, uma ciência-irmã da Embriologia e da Genética surgiu: a Biologia do desenvolvimento (Browder et al., 1991; Gilbert, 2013). Os livros de Embriologia, além da embriologia descritiva tradicional, agregaram esse conteúdo (Montanari, 2013; Carlson, 2014), e surge um dilema no ensino de Embriologia: quanto do "novo", ou seja, da embriologia molecular e quanto do "velho" da embriologia descritiva devem ser ministrados (Carlson, 2002).

Apesar do mercado de trabalho exigir mais domínio dessa matéria e o volume de 
informação ser cada vez maior, há uma constante redução na carga horária para o seu ensino, assim como de outras disciplinas da área morfológica nos cursos de graduação. Diminuição de aulas teóricas ou práticas e até mesmo aglutinação da Embriologia com outras disciplinas da Morfologia têm sido realizadas recorrentemente nas reformas curriculares. Uma situação encontrada em diversas escolas de ensino superior (Carlson, 2002; Heidger et al., 2002; Samar \& Avila, 2007; Ferreira \& Kempinas, 2010; Ferreira, 2011; Santa-Rosa \& Struchiner, 2011).

A construção de ferramentas de educação a distância surge como alternativa para complementar a educação presencial e otimizar o tempo do professor e do aluno no processo de ensino-aprendizagem (Samar \& Avila, 2007; Ferreira \& Kempinas, 2010; Ferreira, 2011; Santa-Rosa \& Struchiner, 2011). As tecnologias da informação e da comunicação permitem enriquecer as situações educativas e favorecem a aprendizagem pela busca, experimentação e transformação do conhecimento, sem o condicionamento temporal ou espacial e respeitando o tempo biológico individual para processar a informação. $O$ aluno tem um papel ativo na construção do conhecimento, desenvolvendo de maneira progressiva uma independência cognitiva que permitirá enriquecer seu desempenho profissional futuro (Avila et al., 2004; Samar \& Avila, 2007). A interação do sujeito com o objeto contribui para a assimilação, já que envolve o interesse, a iniciativa e o esforço pessoal na realização da ação (Piaget, 1976; Piaget, 1998).

Avila et al. (2004), no planejamento de um laboratório virtual para o ensino de Embriologia Humana na Universidad Nacional de Córdoba, colocaram entre as metas: promover a difusão dos resultados dos projetos científicos e expandir a população estudantil através da web, rompendo as barreiras da distância, fronteiras ou posse do material de estudo. Resultados também atingidos por este recurso educacional. $\mathrm{O}$ material acumulado em anos de carreira docente e de pesquisa foi divulgado "fora dos muros da escola". Como se pode constatar pelo ClustrMaps, o auladeembrio é acessado também em outras cidades do estado e do país e inclusive no exterior, o que demonstra a sua receptividade e aceitação.

Pela oferta de informação atualizada, apresentada prioritariamente em linguagem visual e com recursos de interatividade, publicada livremente na rede, espera-se ter contribuído para a qualificação do ensino de Embriologia, e, por conseguinte, das Ciências Morfológicas.

\section{CONCLUSÕES}

O ambiente virtual auladeembrio (http://www.ufrgs.br/auladeembrio) foi desenvolvido para apoiar o processo de ensino-aprendizagem de Embriologia nos cursos de graduação nas áreas Biológicas e da Saúde. Espera-se atingir, como público-alvo, também os alunos e professores do ensino médio. A construção de um recurso virtual sobre Embriologia é justificada pela pouca disponibilidade de bibliografia sobre desenvolvimento comparado e de material qualificado na rede. $O$ estudo remoto complementa o ensino presencial, pressionado pela redução na carga horária, e torna o aluno sujeito no processo cognitivo. O conteúdo é exibido em telas do PowerPoint, ilustrado com fotografias macroscópicas ou obtidas em microscópio estereoscópico, de luz ou eletrônico e desenhos realizados com o Adobe Illustrator. Além do texto narrativo e das legendas, foram incluídos tabelas e mapas conceituais para facilitar a compreensão. Para aumentar a interatividade e motivar a aprendizagem, foram agregados exercícios desenvolvidos com o Hot Potatoes. O recurso educacional tem 
sido utilizado na disciplina de Embriologia do curso de Ciências Biológicas, sendo instrumento importante no processo didático-pedagógico. A Embriologia humana e comparada é abordada nas aulas práticas com a representação de preparados permanentes e atividades de modelagem. $\mathrm{O}$ auladeembrio, acessado por dispositivos móveis é a referência de apoio. A avaliação discente constatou sua contribuição para a aprendizagem através da linguagem visual e dos recursos de interatividade. A importância da representação em modelagem para o entendimento do desenvolvimento animal no ensino médio e superior também foi ponderada pelos alunos. Nas ilustrações e nos moldes em massa de modelar, a coerência das cores nas etapas progressivas permite acompanhar a regionalização do ovo, o posicionamento das células-filhas durante a clivagem, os movimentos morfogenéticos sofridos na gastrulação e a localização dos folhetos embrionários e dos seus derivados. Com o desenvolvimento desse recurso virtual, espera-se ter contribuído para a qualificação do ensino das Ciências Morfológicas.

\section{AGRADECIMENTOS}

À Profa Eliane de Oliveira Borges, especialista em Informática em Educação (CINTED, UFRGS), técnica-administrativa do Departamento de Fisiologia, pela orientação nos programas Adobe Illustrator e Hot Potatoes e pelo desenvolvimento da navegação do ambiente virtual.

Aos acadêmicos: Sofia Louise Santin Barilli, pelo registro fotográfico do acervo de embriões e fetos humanos da disciplina e dos fetos de camundongo dos seus experimentos de embriofetotoxicidade e pela digitalização das fotomicrografias; Luna Camargo Pesce, pela digitalização de imagens dos livros-texto; Tainã Gonçalves Loureiro e Elise Leite, pelas ilustrações com o Adobe Illustrator, e Paola Graciela dos Santos Morais, pela confeccção de exercícios com o Hot Potatoes.

À Pró-Reitoria de Graduação e à Secretaria de Educação a Distância (SEAD), pelas bolsas do Programa de monitoria à distância para disciplina presencial a Luna Camargo Pesce (2009), Paola Graciela dos Santos Morais (2009 e 2010) e Tainã Gonçalves Loureiro (2010), e à SEAD, pela bolsa para desenvolvimento de objeto de aprendizagem para Elise Leite (2010).

\section{REFERÊNCIAS BIBLIOGRÁFICAS}

AVILA, R. E.; SAMAR, M. E.; PEÑALOZA, S. F. Creación de um laboratório virtual para la enseñanza universitária de la Embriologia humana em sus aspectos biológicos, éticos y sociales. In: CONGRESO VIRTUAL LATINOAMERICANO DE EDUCACIÓN A DISTANCIA, 1. 2004.Disponível em: 〈http://www.ateneonline.net/datos/10_01_Avila_Rodolfo_y_otros.pdf >. Acesso em: 11 abril 2014.

BALINSKY, B. I. Introduction to embryology. 5.ed. Philadelphia: Saunders College, 1981. $768 \mathrm{p}$.

BRITO, C. Zika virus: a new chapter in the History of Medicine. Acta Medica Portuguesa, v. 28, n. 6, pp. 679-680, nov-dec 2015. Disponível em:

<http://www.actamedicaportuguesa.com/revista/index.php/amp/article/view/7341/4565>.

Acesso em: 4 maio 2017.

BROWDER, L. W.; ERICKSON, C. A.; JEFFERY, W. R. Developmental Biology. Philadelphia: Saunders College, 1991. 812 p. 
CARLSON, B. M. Embryology in the medical curriculum. The Anatomical Record, v. 269, n. 2, p. 89-98, 2002.

CARLSON, B. M. Human Embryology and Developmental Biology. 5.ed. Philadelphia: Elsevier Saunders, 2014. 506 p.

FERREIRA, A. S. S. B. S.; KEMPINAS, W. de G. Avaliação de um ambiente virtual de ensino de apoio à educação presencial em curso de graduação em Biologia. In: CONGRESSO INTERNACIONAL DE EDUCAÇÃO A DISTÂNCIA, 16., Foz do Iguaçu, 2010. Anais. Foz do Iguaçu: Associação Brasileira de Educação a Distância, 2010. Disponível em: <http://www.abed.org.br/congresso2010/cd/2152010154536.pdf〉. Acesso em: 09 set. 2017.

FERREIRA, A. S. S. B. S. Elaboração e avaliação de um ambiente virtual para o ensino/aprendizagem de Embriologia. Botucatu: UNESP, 2011. 90 p. Tese de Doutorado. Disponível em: <http://www.ibb.unesp.br/posgrad/teses/bga_do_2011_ana_ferreira.pdf >. Acesso em: 09 set. de 2017.

GARCIA, S. M. L.; GARCIA, C. F. Embriologia. 3.ed. Porto Alegre: Artmed, 2012. 668 p.

GILBERT, S. F. Developmental Biology. 10.ed. Sunderland: Sinauer Associates, 2013. 719 p.

GILBERT, S. F.; RAUNIO, A. M. (ed.) Embryology: constructing the organism. 10.ed. Sunderland: Sinauer Associates, 1997. 537 p.

GREGG, N. M. Congenital cataract following german measles in mothers. Transactions of the Ophtalmological Society of Australia, v. 3, p. 35, 1941. Disponível em:

<https://www.ncbi.nlm.nih.gov/pmc/articles/PMC2272051/pdf/epidinfect00028-0013.pdf>. Acesso em: 4 maio 2017.

HEIDGER Jr., P. M.; DEE, F.; CONSOER, D.; LEAVEN, T.; DUCAN, J.; KREITER, C. Integrated approach to teaching and testing in Histology with real and virtual imaging. The Anatomical Record, v. 269, p. 107-112, 2002. Disponível em:

<http://onlinelibrary.wiley.com/doi/10.1002/ar.10078/epdf>. Acesso em: 4 maio 2017.

HEYDEN, R. J. Approaches to Cell Biology: developing educational multimedia. Cell Biology Education, v. 3, p. 93-98, 2004. Disponível em:

<https://www.ncbi.nlm.nih.gov/pmc/articles/PMC437640/pdf/03-08-0009_p093.pdf>. Acesso em: 09 set. 2017.

HOUILLON, C. Embriologia. São Paulo: Edgar Blücher, 1972. 160 p.

LENZ, W. Thalidomide and congenital abnormalities (Letters to the editor). Lancet, jan 6, 1962. p. 45. Disponível em: <http://ac.els-cdn.com/S014067366292665X/1-s2.0S014067366292665X-main.pdf?_tid=9401c69a-30e0-11e7-acb2-

00000aab0f26\&acdnat=1493912857_9f8b3db415f0dae238e54d00e51fc27a>. Acesso em: 4 maio 2017.

MAYER, R. E.; GALLINI, J. K. When is an illustration worth ten thousand words? Journal of Educational Psychology, v. 82, n. 4, p. 715-726, 1990.

McBRIDE, W. G. Thalidomide and congenital abnormalities (Letters to the editor). Lancet, dec 16, 1961. p. 1358. Disponível em: <http://ac.els-cdn.com/S0140673661909278/1-s2.0S0140673661909278-main.pdf?_tid=21f2d132-30e2-11e7-97f5-

00000aab0f01\&acdnat=1493913524_dc5a8d9a67f68185b70ae8f98428645c >. Acesso em: 4 maio 2017.

MCCLEAN, P.; JOHNSON, C.; ROGERS, R.; DANIELS, L.; REBER, J.; SLATOR, B. M.; TERPSTRA, J.; WHITE, A. Molecular and cellular Biology animations: development and impact on student learning. Cell Biology Education, v. 4, p. 169-179, 2005. Disponível em: <https://www.ncbi.nlm.nih.gov/pmc/articles/PMC1103718/pdf/11536-7509-4-2-169.pdf>.

Acesso em: 09 set. 2017.

MONTANARI, T. Embriologia: texto, atlas e roteiro de aulas práticas. Porto Alegre: Ed. da autora, 2013. Disponível em: <http://www.ufrgs.br/livrodeembrio>. Acesso em: 09 set. 2017.

PFEIFFER, R. A.; KOSENOW, W. Thalidomide and congenital abnormalities (Letters to the editor). Lancet, jan 6, 1962. p. 45-46. Disponível em: <http://ac.els- 
cdn.com/S014067366292665X/1-s2.0-S014067366292665X-main.pdf?_tid=9401c69a-30e011e7-acb2-00000aab0f26\&acdnat=1493912857_9f8b3db415f0dae238e54d00e51fc27a>.

Acesso em: 4 maio 2017.

PIAGET, J. Psicologia e Pedagogia. 4.ed. Rio de Janeiro: Forense Universitária, 1976. p. 37, 48.

PIAGET, J. Sobre Pedagogia. São Paulo: Casa do Psicólogo, 1998. p. 138-139, 149.

SAMAR, M. E.; AVILA, R. E. Materiales instruccionales en la enseñanza virtual de la histologia y embriologia humana. In: CONGRESO VIRTUAL HISPANOAMERICANO DE ANATOMÍA PATOLÓGICA, 9. y CONGRESSO DE PREPARACIONES VIRTUALES POR INTERNET, 2., 2007, Ciudad Real. Anais. Ciudad Real: Universidad de Castilla La Mancha y Complejo Hospitalario de Ciudad Real. 2007. Disponível em:

$<\mathrm{http}: / /$ www.conganat.org/9congreso/trabajo.asp?id_trabajo=688\&tipo=2 $>$. Acesso em: 09 set. 2017.

SANTA-ROSA, J. G.; STRUCHINER, M. Tecnologia educacional no contexto do ensino de Histologia: pesquisa e desenvolvimento de um ambiente virtual de ensino e aprendizagem. Revista Brasileira de Educação Médica, v. 35, n. 2, p. 289-298, 2011. Disponível em: <http://www.scielo.br/pdf/rbem/v35n2/20.pdf >. Acesso em: 09 set. 2017.

STITH, B. J. Use of animation in teaching Cell biology. Cell Biology Education, v. 3, p. 181188, 2004. Disponível em: <https://www.ncbi.nlm.nih.gov/pmc/articles/PMC520841/pdf/i15367509-3-3-181.pdf>. Acesso em: 09 set. 2017.

WOLPERT, L.; JESSELL, T.; LAWRENCE, P.; MEYEROWITZ, E.; ROBERTSON, E.; SMITH, J. Princípios de Biologia do Desenvolvimento. 3.ed. Porto Alegre: Artmed, 2008. 576 p. 